\title{
Oxygen therapy in acute MI- role uncertainty
}

Amanda Burls BA, MSc, MBBS, FFPH* Juan B Cabello MD, PhD †, Jose I Emparanza MD, PhD ‡, Sue Bayliss BA (Hons) §, and Tom Quinn MPhil, RN, FESC, FRCN ||

*Department of Primary Health Care, University of Oxford, Oxford, UK;

† Departamento de Cardiologia \& CASP Spain Hospital General Universitario de Alicante, Spain;

‡ Unidad Epidemiologica Clinica, CASP Spain, CIBER-ESP, Hospital Donostia, San Sebastian, Spain;

${ }^{\S}$ West Midlands Health Technology Assessment Collaboration, University of Birmingham, Birmingham, UK; and

|| Faculty of Health and Medical Sciences, University of Surrey, Guildford, UK

\section{Corresponding author:}

Professor Tom Quinn, Faculty of Health and Medical Sciences, Duke of Kent Building, University of Surrey, Guildford GU2 7TE, UK

Telephone: +44 (0)1483684553

Email: t.quinn@surrey.ac.uk

Keywords: acute myocardial infarction, oxygen, outcomes, systematic review, pre-hospital care . 


\section{Background}

Administration of inhaled oxygen to patients with acute myocardial infarction (MI) has been recommended in national and international guidelines (Kallstrom 2002, American Heart Association 2004, American Heart Association 2005, International Liaison Committee on Resuscitation 2005, Anderson et al 2007, Antman et al 2004, , Van de Werf 2007) and has been a mainstay of pre-hospital management for decades. Compliance with guideline recommendations is high: in a 2007 survey of over 500 UK emergency departments, cardiology and ambulance staff $98.3 \%$ reported always or usually using oxygen in patients suffering a heart attack. (Burls et al 2010) Similarly $86 \%$ of Spanish cardiologists responding to a parallel survey $(\mathrm{N}=169)$ reported routinely using oxygen in uncomplicated MI. (Cabello et al 2010)

Emerging UK guidelines are beginning to diverge from the previous consensus that oxygen should routinely be administered in AMI. For example, the Scottish Intercollegiate Guidelines Network (SIGN, 2008) restricts recommendations on oxygen in acute coronary syndrome (ACS) to use with hypoxic patients and those with pulmonary oedema or continuing myocardial ischaemia. They make clear that this is based on expert opinion alone. The recent British Thoracic Society (2008) guidelines on emergency oxygen use in adult patients, recommend that $\mathrm{AMI}$ patients should receive oxygen only if hypoxaemic, a recommendation again based on expert consensus rather than hard evidence. The Joint Royal Colleges Ambulance 
Liaison Committee (JRCALC, 2010) and more recently the National Institute for Health and Clinical Excellence (NICE, 2010) have used a similar formulation in their respective guidelines.

\section{What is the evidence that oxygen is harmful or beneficial in AMI?}

A number of systematic reviews in recent years have cast doubt on the safety and efficacy of oxygen in AMI, citing various possible mechanisms by which harm may be induced. However, the evidence either way is weak.

Nicholson (2004) from the UK reviewed human studies, some nonrandomised, concluding that oxygen administration did not reduce acute myocardial ischaemia, with some evidence suggesting that it may actually increase ischaemia.

Wijesenghe et al (2008) from New Zealand reviewed the effect of oxygen on infarct size and concluded: "There is little evidence by which to determine the efficacy and safety of high flow oxygen therapy in MI. The evidence that does exist suggests that the routine use of high flow oxygen in uncomplicated MI may result in a greater infarct size and possibly increase the risk of mortality."

From the same group, Farquhar et al (2009) reported a systematic review of studies measuring coronary blood flow, concluding that hyperoxia from highconcentration oxygen therapy caused marked reduction in coronary blood flow and myocardial oxygen consumption. 
A recent Cochrane systematic review undertaken by the present authors brought the evidence up to date by including a trial from Russia, in the primary $\mathrm{PCl}$ era, that had not been identified by authors of previous evidence syntheses. We found only three trials out of more than 2500 studies identified through a comprehensive search of the literature. These three trials (one each from the pre-thrombolysis, thrombolysis and primary $\mathrm{PCl}$ eras) together recruited a total of 387 patients, of whom 14 died. The combined relative risk $(\mathrm{RR})$ of death in those receiving oxygen compared with air was $2.88(95 \% \mathrm{Cl}$ 0.88 to 9.39$)$ in an intention-to-treat analysis and $3.03(95 \% \mathrm{Cl} 0.93$ to 9.83$)$ in patients with confirmed AMI.

While suggestive of harm, it is important to recognise that the small number of deaths could be a chance occurrence. No difference was found in pain measured by analgesic use: the pooled RR for use of analgesics was 0.97 (95\% Cl 0.78 to 1.20 ). (Cabello et al 2010) Publication of our review prompted the British Heart Foundation (2010) to revise their position on the role of oxygen in $\mathrm{AMI}$ and to call for more research in this area. A BMJ editorial commissioned to coincide with publication of our review recommended that oxygen continue to be routinely used based on pathophysiological reasoning (Atar 2010) although this has led to considerable correspondence, not least from the authors of the BTS guideline, who have called for the editorial to be retracted. Clearly there is ongoing uncertainty about the role of oxygen in AMI. 


\section{Underlying mechanisms that may be harmful}

It is biologically plausible that oxygen is doing harm. Potentially harmful mechanisms include the paradoxical effect of reducing coronary blood flow and increasing coronary vascular resistance (McNulty et al 2005, McNulty et al 2007); reduced stroke volume and cardiac output (Milone et al 1990); other adverse haemodynamic consequences, such as increased vascular resistance from hyperoxia; and reperfusion injury from increased oxygen free radicals. (Rousseau et al 2005, Farquhar et al 2009)

\section{Ongoing and future trials}

We searched ClinicalTrials.gov and the World Health Organisation International Clinical Trials Registry Platform for ongoing trials of oxygen in AMI and identified two studies, from Australia and New Zealand, neither of which (one hospital based, the other pre-hospital, recruiting 200 patients each) is powered for mortality. We have calculated that around 10 thousand patients would need to be randomised to receive oxygen, and another 10 thousand to air, to address the question of whether oxygen improves or increases mortality. We are therefore working with colleagues from ambulance services, cardiology, emergency medicine and public health to plan such a trial. 


\section{What should the clinician do in the face of ongoing uncertainty about the role of oxygen in AMI?}

In 2010 we still do not know whether routine oxygen administration is beneficial, harmful, or irrelevant in AMI. Nor do we have robust evidence that oxygen is beneficial in 'complicated' patients such as those with shock or arrhythmia. More important than moving from one set of guideline recommendations based on expert opinion to a different set of guideline recommendations based on expert opinion, we need to generate good evidence, from adequately powered randomised controlled trials (RCTs) to guide decisions on which patients across the spectrum of ACS - if any should receive oxygen, at what dose, and for how long. A high quality RCT should urgently be conducted to resolve this uncertainty before more people are either harmed or deprived of benefit.

In the absence of high quality evidence to guide practice, we think it is reasonable for clinicians to follow existing national and international guideline recommendations, which are based on expert consensus, until they are either confirmed or refuted by high quality research. An important role for ambulance clinicians in helping to resolve the ongoing uncertainties about the role of oxygen in AMI/ACS will be to participate, in the context of the regulations governing clinical trials in emergency situations (Shakur et al 2007) in ethically approved RCTs. 


\section{References}

American Heart Association (2005) Guidelines for cardiopulmonary resuscitation and emergency cardiovascular care: Part 8: Stabilization of the Patient With Acute Coronary Syndromes. Circulation 112 (24 Suppl):IV89IV110.

Anderson JL, Adams CD, Antman EM, Bridges CR, Califf RM, Casey DE et al. (2007) ACC/AHA 2007 guidelines for the management of patients with unstable angina/non ST-elevation myocardial infarction: a report of the American College of Cardiology/American Heart Association Task Force on Practice Guidelines. Circulation 116:e148-e304.

Antman EM, Anbe DT, Armstrong PW, Bates ER, Green LA, Hand M et al (2004) ACC/AHA guidelines for the management of patients with STelevation myocardial infarction-executive summary: a report of the American College of Cardiology/American Heart Association. Circulation 110:588-636.

Burls AJ, Emparanza JI, Quinn T, Cabello JB (2010) Oxygen use in acute myocardial infarction - an online survey of health professionals' practice and beliefs. Emerg Med J 27:283-6. 
Cabello JB, Emparanza JI, Ruiz-Garcia V, Burls A (2009) Oxygen therapy for acute myocardial infarction: a web-based survey of physicians' practices and beliefs. Emergencias 21:422-8.

Cabello JB, Burls A, Emparanza JI, Bayliss S, Quinn T (2010) Oxygen therapy for acute myocardial infarction. Cochrane Database Syst Rev 6: CD007160.

Farquhar $\mathrm{H}$, Weatherall M, Wijesinghe $\mathrm{M}$ et al (2009) Systematic review of studies of the effect of hyperoxia on coronary blood flow. Am Heart J. 58:3717.

International Liaison Committee on Resuscitation (2005) Part 5: acute coronary syndromes. Resuscitation 67(2-3):249-269.

Kallstrom T. (2002) American Association for Respiratory Care (AARC). AARC Clinical Practice Guideline: oxygen therapy for adults in the acute care facility--2002 revision \& update. Respiratory Care 47:717-720.

Milone SD, Newton GE, Parker JD (1999). Hemodynamic and biochemical effects of $100 \%$ oxygen breathing in humans. Can J Physiol Pharmacol 77:124-30.

McNulty PH, King N, Scott S et al (2005) Effects of supplemental oxygen administration on coronary blood flow in patients undergoing cardiac catheterization. Am J Physiol Heart Circ Physiol 288:H1057-H1062. 
McNulty PH, Robertson BJ, Tulli MA et al (2007) Effect of hyperoxia and vitamin $\mathrm{C}$ on coronary blood flow in patients with ischemic heart disease. $\mathrm{J}$ Appl Physiol 102:2040-5.

National Institute for Health and Clinical Excellence (2010). Chest pain of recent onset. Assessment and diagnosis of recent onset chest pain or discomfort of suspected cardiac origin. London, NICE clinical guideline 95.

Nicholson C. (2004) A systematic review of the effectiveness of oxygen in reducing acute myocardial ischaemia. Journal of Clinical Nursing 13:9961007.

O'Driscoll BR, Howard LS, Davison AG (2008). British Thoracic Society guideline for emergency oxygen use in adult patients. Thorax 63 Suppl 6:vi168.

Rousseau A, Bak Z, Janerot-Sjoberg B, Sjoberg F (2005). Acute hyperoxaemia-induced effects on regional blood flow, oxygen consumption and central circulation in man. Acta Physiol Scand 183:231-40.

Scottish Intercollegiate Guidelines Network (2007). Acute coronary syndrome. A national clinical guideline. http://www.sign.ac.uk/pdf/sign93.pdf.

Shakur H, Roberts I, Barnetson L, Coats T. Clinical trials in emergency situations. BMJ. 2007;334:165-6. 
Van de Werf F, Bax J, Betriu A, Blomstrom-Lundqvist C, Crea F, Falk V et al. (2008) Management of acute myocardial infarction in patients presenting with persistent ST-segment elevation: the Task Force on the Management of STSegment Elevation Acute Myocardial Infarction of the European Society of Cardiology. Eur Heart J 29:2909-2945.

Wijesinghe M, Perrin K, Ranchord A, Simmonds M, Weatherall M, Beasley R (2009). The routine use of oxygen in the treatment of myocardial infarction: systematic review. Heart 95:198-202 